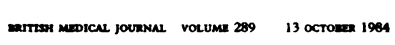
PRACTICE OBSERVED

\section{Practice Research}

\section{Health of prisoners admitted to and discharged from Bedford Prison}

EDWIN MARTIN, MARTIN COLEBROOK, ANDREW GRAY

Abstract

The age, amoling and drinking habits, active bealth

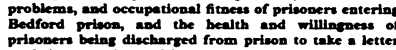

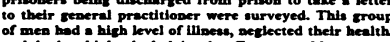

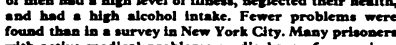

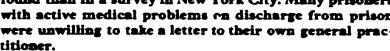

Introdection

It has been sugessed that age for age prisoners experience
higher incidence of most illnesses than the general population

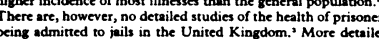

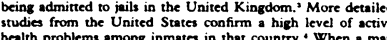
healch problems among inmates in that country. When a man
enters prison many of his tiberties are caken away and he
becomes dependent for his most bessic needs on those who rue

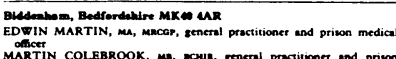

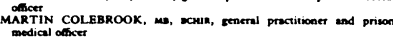

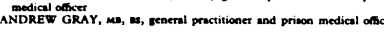

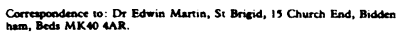

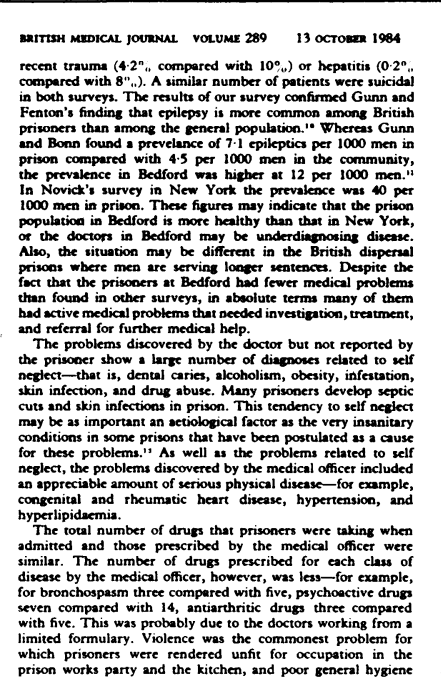

\title{
Comparison of medical care in prison and in general
} practice

EDWIN MARTIN

Abstract

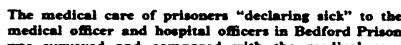

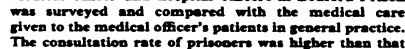

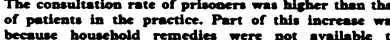

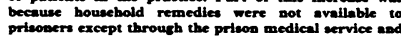

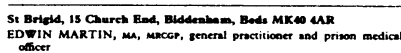

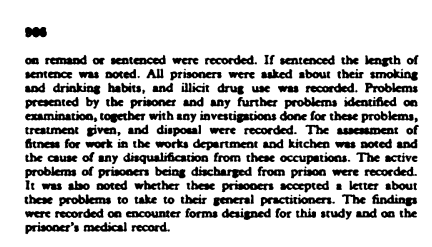

Resules

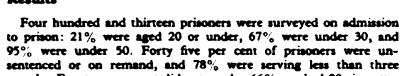

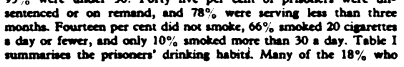

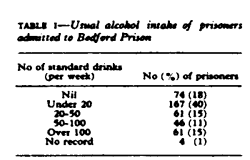

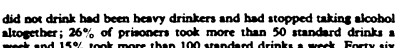

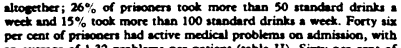

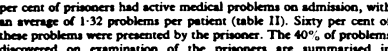

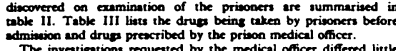

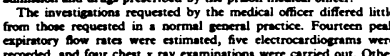

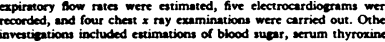

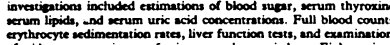

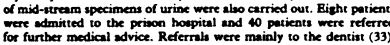

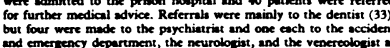

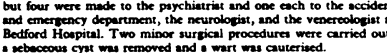

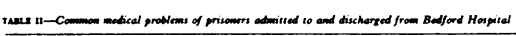

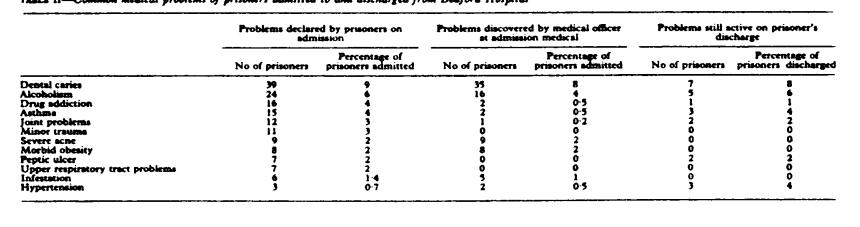

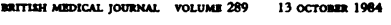

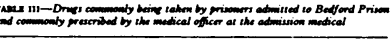

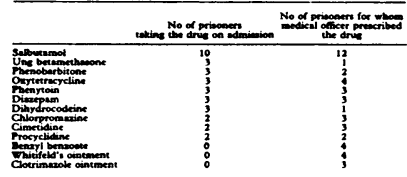

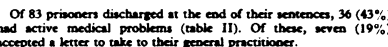
Diecuestion

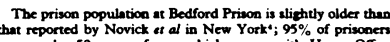

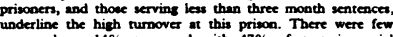

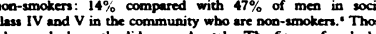

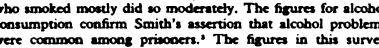

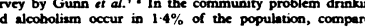

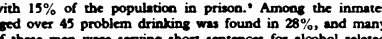

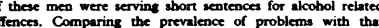

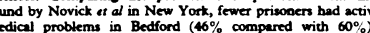

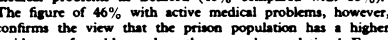

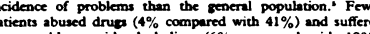

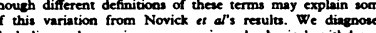

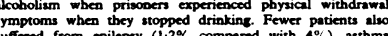

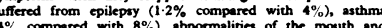

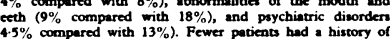

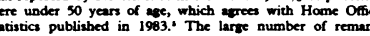

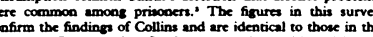

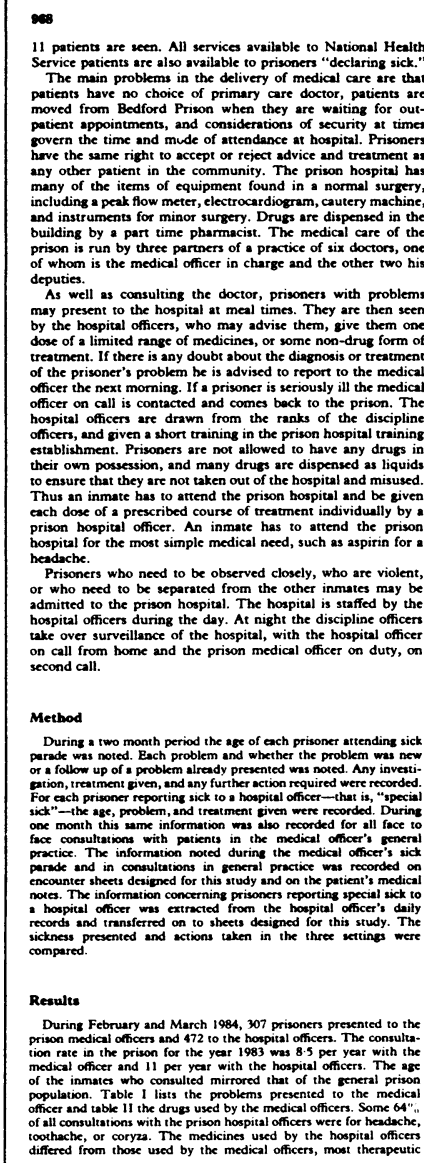

was the commonest problem rendering a prisoner unfit for work in the kitchen.
Oaly $19 \%_{0}$ of prisoners with active problems on diecharse

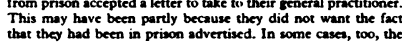

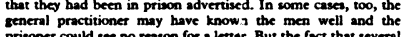
prisoner could see no resson for a leterter. But the farct that several
prisoners with serious problems that had been diagnoedd in

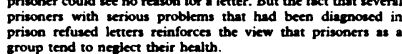

\section{Coscluation}

In this local prison the population is medc up disproportionerely of men who drink heavily and who smoke. They also have more

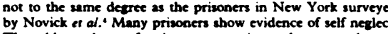

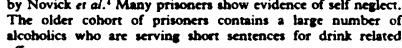
References

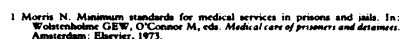

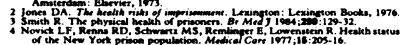

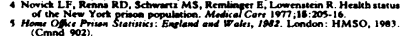

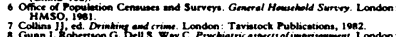

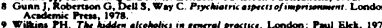

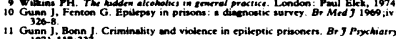

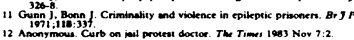

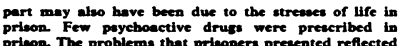

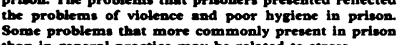
latroduction Bedford Prion has an average population of 331 inmates. In
another

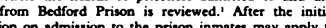

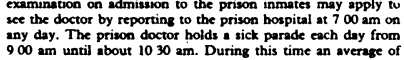

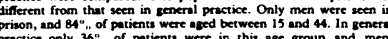

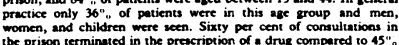

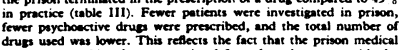

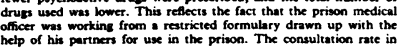

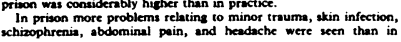

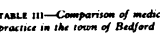

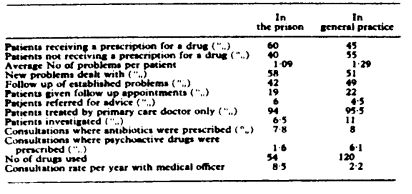

